\title{
Kinematic differences on mid-range basketball jump-shot between experienced and less-experienced collegiate player
}

\author{
Agam Akhmad Syaukani ${ }^{1}{ }^{*}$, Li Chun Yan ${ }^{2}$ \\ ${ }^{1}$ Program Studi Pendidikan Olahraga, Fakultas Keguruan dan Ilmu Pendidikan, Universitas \\ Muhammadiyah Surakarta. Jalan Ahmad Yani, Pabelan, Kartasura, Jawa Tengah 57162, Indonesia. \\ ${ }^{2}$ Department of Kinesiology, Postgraduate Programs, Wuhan Sports University. \\ No.461 Luoyu Road, Wuhan City, Hubei Province, 430079, PR China \\ * Corresponding Author. Email: aas622@ums.ac.id \\ Received: 11 October 2018; Revised: 7 November 2018; Accepted: 17 November 2018
}

\begin{abstract}
Jump shot in modern basketball is an effective scoring way to overcome pressure of the defender. Fundamental jump shot technique relies on experience and biomechanical analyses. The purpose of this analysis was to evaluate kinematic profile of basketball players based on their experience level during midrange jump shot. Four experienced basketball players and four less-experienced basketball players participated in the experiment. Jump shot phase was classified into 3 categories: preparatory, action, and follow-through. Angular displacement and angular velocity were measured using three-dimension (3D) motion capture technology. Assumption test was previously taken to determine data normality using K-S and homogeneity using levene test. Data were normally distributed and homogen. One-way Anova analysis indicated significant differences on several kinematic parameters between groups. On preparatory phase, experienced subject produced larger magnitude for right-shoulder extension $\left(-10.3 \pm 14.7^{\circ}\right)$ and produced smaller angular velocity for hips flexion $\left(41.0 \pm 11.6^{\circ} / \mathrm{s}\right)$. During the action phase, experienced subject produced larger magnitude for right-wrist flexion $\left(-145.9 \pm 40.3^{\circ}\right)$, larger angular velocity for right-wrist flexion $\left(-182.8 \pm 35.7^{\circ} / \mathrm{s}\right)$, larger angular velocity for ankle plantar flexion $\left(-159.5 \pm 27.3^{\circ} / \mathrm{s}\right)$, and larger angular velocity for right-elbow extension $(-149.6 \pm 33.3 \%)$. The findings of this study indicated that improper mechanics of basketball jump shot existed in less-experienced players. To practice jump shot technique, preparatory phase and action phase should be the main emphasis for every coach when deals with lessexperienced player.
\end{abstract}

Keywords: jump shot, kinematics, angular displacement, angular velocity

How to Cite: Syaukani, A., \& Yan, L. (2019). Kinematic differences on mid-range basketball jump-shot between experienced and less-experienced collegiate player. Jurnal Keolahragaan, 7(1), 1-10. doi:https://doi.org/10.21831/jk.v7i1.21541

do

https://doi.org/10.21831/jk.v7i1.21541

\section{INTRODUCTION}

Basketball has been through so many developmental changes since it was first introduce in 1891 by James Naismith. Modification carried on the rule of game has added attractiveness to the game for players and audience. Academic research also helps basketball to develop through a series of experiments focusing on biomechanical aspects towards the existing basketball skill to refine and successfully apply certain skill. Therefore, basketball becomes more appealing and high-scoring and intense game over a period of time. It is important that teachers and coaches combine their practical experience with latest biomechanics research to facilitate their training. Thus, it can explore the best performance of their athlete (Knudson, 1993). Jump shot has been considered important in a basketball game (Çetin \& Muratl1, 2014; Hess, 1980). As the game becomes further driven and the athletic capability of the player is rising, the defence is now become more tight and intense. As a result, jump shot has become a common technique to overcome tight defence and make score. Jump shot comes as a breakthrough on offensive attempt to score despite the tight defence that might challenge every effort on scoring (Wissel, 2011). Jump shot has amounting to over $70 \%$ of all the shots during a game (Struzik, Pietraszewski, \& Zawadzki, 2014). Jump shot effectiveness was described by Rojas, 
Cepero, Ona, \& Gutierrez (2000) in his investigation which recorded that $41 \%$ of score during Spanish Basketball League were obtained from jump shot and its variation.

Given the importance of jump shot, many studies have adopted this technique into various biomechanical study and analyses, while only few studies have observed whole body kinematic trait during jump shot execution. Comparative study also been performed to address effect of different distance, ball size, and gender on jump shot kinematic characteristic. However, no study had been established to link between kinematic traits during jump shot execution with player experience at collegiate level. To date, kinematic study has been made progress and proved to be beneficial to analyse every motion involved in sport skills.

Kinematic markers can help to understand functional alterations in movement selection used in target-related task (Button, Macleod, Sanders, \& Coleman, 2003), for instance, in different distance of shooting, kinematic adjustment had reached a complete technical combination both the vertical displacement and horizontal displacement task with strategy of higher speed of release and lower angle of release (Okazaki \& Rodacki, 2012). To our knowledge, it is still unknown how player experience determining the selection of movement strategy during the jump shot execution. Hence, the objective of this investigation is to mark the kinematic differences between experienced players and less-experienced players in collegiate level basketball players regarding of mid-range basketball jump shot. This research came up with hypothesis that there are differences on kinematical profile between experienced and less-experienced player during execution of mid-range basketball jump shot.

\section{METHODS}

\section{Participants and Experimental Design}

The investigation was organized among 8 collegiate basketball players. Four experienced basketball players were characterized by the following mean properties $( \pm \mathrm{SD})$ : body height $178.50 \pm 6.03 \mathrm{~cm}$, body mass $71 \pm 6.58 \mathrm{~kg}$, age $19.25 \pm 0.5$ years and four less-experienced players (height $178.25 \pm 8.06 \mathrm{~cm}$; body mass $68.75 \pm 8.81 \mathrm{~kg}$; age $19.75 \pm 1.50$ years). All of the participants were right-handed shooters and familiar with jump shot technique. They were considered having a normal BMI. The experienced basketball players had took part in basketball for 8-12 years. They are undergraduate students who are majoring in basketball training in Wuhan Sports University (practice hours 12.75 \pm 1.893 $\mathrm{h} /$ week). They are member of college basketball team. None of the experienced participants were professionals. The less-experienced basketball players are undergraduate students other than from basketball major (practice hours $5.5 \pm 1 \mathrm{~h} /$ week). None of thfe less-experienced participants had received special training in basketball. However, they have been engage with basketball as a recreational sports for maximum 3 years. All participants declared no presence of injury prior to data obtaining procedure. They were all wearing basketball shoes typically used for practice and competition. Additionally, all participants were required to give their informed consent for participation on the experiment after being explained of the aim and associated risk for this study. The Ethics Committee on Sports and Exercise Research of The Wuhan Institute of Physical Education approved this study.

All participants were instrumented with thirty-six reflective markers (9-mm in diameter) attached to the anatomical landmarks of each subject's body: right and left frontal and parietal bone intersection, right and left back head, $7^{\text {th }}$ cervical vertebrae, $10^{\text {th }}$ thoracic vertebrae, clavicle (sternal end), right back (infraspinous fossa), right and left acromion process, right and left medial forearm, right left olecranon, right and left medial forearm, right and left styloid process of radius and ulna, right and left $3^{\text {rd }}$ metacarpal, right and left anterior iliac spine, right and left posterior iliac spine, right and left thigh, right and left knee, right and left lateral tibia, right and left lateral malleolus, right and left posterior calcaneal tuberosity, right and left $3^{\text {rd }}$ metatarsal. Markers were utilized to established subject's 3D model for further kinematic analysis.

Experiment was conducted in standard indoor basketball court with eight-camera, Vicon MX system (Vicon ${ }^{\circledR}$, Oxford, UK) was utilized to record kinematic data from participants' body. Cameras were positioned on half-court around subject's standing position on the free-throw area to capture jump shot movement from the subject. A frame rate of $100 \mathrm{~Hz}$ was used in this experiment. Participants were requested to do ten jump shot from stationery position in the free throw area or $4.6 \mathrm{~m}$ distance from the backboard since it was determined from previous study that mid-range jump shot provide the most accuracy percentage (Okazaki \& Rodacki, 2012). Participants were inquired to do warm-up and 
Jurnal Keolahragaan 7 (1), 2019 - 3

Agam Akhmad Syaukani, Li Chun Yan

familiarisation before data collection. They were also asked to take their own pace while performing the jump shots. In order to ease kinematical analysis process, one successful jump shot of every subject during data recording, defined as the ball executed with jumping and shooting goes into the basket as a result of jump shot were selected as the object of analysis. Further kinematic analysis to determine movement pattern were conducted among several variables around the ankle, knee, hip, trunk, shoulder, elbow, and wrist joints and the following determined variables: (1) temporal series of angular displacement and velocity; (2) joint range of motion; (3) movement duration, (4) minimum and maximum joint angular displacement, (5) minimum and maximum joint angular velocity. The joint angles kinematic profile were measured continuously regardless of the movement phase involved. Movement phase was identified during data extraction. The only focus on this study is subject's kinematic trait during jump shot performance. Therefore, no reflective markers were placed on the ball. However, an inflated standard basketball (size 7) officially permitted by the International Basketball Federation (FIBA) was used.

\section{Data Analysis}

The Vicon ${ }^{\circledR}$ camera captured 100 frames per second and literally to be the raw data material for further kinematic analysis utilized designed software. Reconstructed threedimensional model of all reflective markers were documented using Vicon ${ }^{\circledR}$ Nexus 2.2. The recorded spatial coordinates were subsequently used to calculate relative segment orientation angles as well as global coordinate orientation angles. Joint kinematics were assessed with the Plug in Gait's calculation protocol (Vicon ${ }^{\circledR}$, Oxford, UK) according to the Newington-Helen Hayes gait simulation that computed joint kinematics from XYZ marker positions and particular subject anthropometric quantity (Michaud-Paquette, Magee, Pearsall, \& Turcotte, 2011). Within data cal-culation process, during Plug in Gait's protocol, 3-D reconstructed stick frame of subject's anatomy were subsequently being digitized based on their XYZ coordinate position and being imported to Microsoft ${ }^{\circledR}$ Excel output for further statistical analysis.

\section{Statistical Analysis}

One-way ANOVA was used to address the potential significant differences in kinematic va- riables between two groups of subject. Assumption test was previously taken to determine data normality using K-S and homogeneity using levene test. Statistical analysis was organized using IBM SPSS Statistic 23 for Windows (SPSS, Chicago, Ill). The statistical significance of difference was established with a $5 \%$ margin of error $(\mathrm{p}<0.05)$.

\section{RESULTS AND DISSCUSSION}

\section{Results}

According to data normality test using Kolmogorov Smirnov (K-S) data found in this study were following a normal distribution (pvalue $>\alpha$ ). Regarding on temporal parameters, there is no significant difference observed on shooting duration and percentage of total duration between two groups. (Table 1). Table 2 shows mean of angular displacement from seven joint angles related to jump shot during preparatory, action, and follow-through (shortly after ball leaves the hand) phase between groups. The mean angular displacement of right shoulder joint during preparatory phase of the experienced group and that of the less-experienced group was $-10.3 \pm 14.7^{\circ}$ and $25.9 \pm 13.7^{\circ}$, respectively. The mean angular displacement of right shoulder joint during preparatory phase of the experienced group was significantly larger than that of the less-experienced group $(\mathrm{P}<0.05)$. The mean angular displacement of right wrist joint during action phase of the experienced group and that of the less-experienced group was $-145.9 \pm 40.3^{\circ}$ and $-42.2 \pm 22.6^{\circ}$, respectively. The mean angular displacement of right wrist joint during action phase of the experienced group was significantly larger than that of the less-experienced group ( $\mathrm{P}$ $<0.05)$.

Table 3 shows mean of angular velocity from seven joint angles related to jump shot during preparatory, action, and follow-through phase between groups. The mean angular velocity of hip joint during preparatory phase of the experienced group and that of the lessexperienced group was $41.0 \pm 11.6 \%$ and $98.7 \pm 31.6 \%$, respectively. The mean angular velocity of hip joint during preparatory phase of the experienced group was significantly slower than that of less-experienced group $(\mathrm{P}<0.05)$. The mean angular velocity of ankle joint during action phase of the experienced group and that of the less-experienced group was $-159.5 \pm 27.3 \%$ and $-110.0 \pm 20.8 \%$, respectively. The mean angular velocity of ankle joint during action 
Jurnal Keolahragaan 7 (1), 2019 - 4

Agam Akhmad Syaukani, Li Chun Yan

phase of the experienced group was significantly faster than that of less-experienced group (P < $0.05)$. The mean angular velocity of right elbow joint during action phase of the experienced group and that of the less-experienced group was $-149.6 \pm 33.3 \%$ and $-80.2 \pm 36.0 \%$, respectively. The mean angular velocity of right elbow joint during action phase of the experienced group was significantly faster than that of less-experienced group $(\mathrm{P}<0.05)$. The mean angular velocity of right wrist joint during action phase of the experienced group and that of the lessexperienced group was $-182.8 \pm 35.7 \%$ and $80.2 \pm 36.0 \%$, respectively. The mean angular velocity of right wrist joint during action phase of the experienced group was significantly faster than that of less-experienced group $(\mathrm{P}<0.05)$.
Figure 1 shows the time-series changes of mean joint angular displacement of the rightwrist joint and right-shoulder joint between experienced group and less-experienced group during jump shots performance. Figure 2 shows the time series changes of mean joint angular velocity of the ankle joint and hip joint between experienced group and less-experienced group during jump shots performance. Figure 3 shows the time series changes of mean joint angular velocity of right-elbow joint, and right-wrist joint between experienced group and less-experienced group. The selected joint angle displayed in Figure 1, Figure 2, and Figure 3 has showed significant difference with $p$-value $<0.05$.

Table 1. Selected Temporal Parameters (mean $\pm s$ )

\begin{tabular}{llll}
\hline & Experienced & Less-experienced & $p$-value \\
\hline Duration of phases $\left(.10^{-2} \mathrm{~s}\right)$ & & & .05 \\
Preparatory & $49 \pm 12.7$ & $27.8 \pm 12.1$ & .32 \\
Action & $67 \pm 15.2$ & $78.8 \pm 15.8$ & .35 \\
Follow-through & $35.8 \pm 4.3$ & $33.5 \pm 0.6$ & .14 \\
Total & $155 \pm 14.3$ & $140 \pm 10.1$ & .09 \\
Percent of total duration & & & .06 \\
Preparatory & $31.7 \pm 8.3$ & $19.9 \pm 8.7$ & .79 \\
Action & $42.9 \pm 6.4$ & $56.1 \pm 9.1$ & $24 \pm 1.6$ \\
Follow-through & $23.3 \pm 4.8$ & & \\
\hline
\end{tabular}

Table 2. Angular Displacement Data (mean \pm s) for Basketball Players with Different Experience Level

\begin{tabular}{|c|c|c|c|}
\hline & Experienced & Less-experienced & $p$-value \\
\hline \multicolumn{4}{|l|}{ Preparatory $\left({ }^{\circ}\right)$} \\
\hline ankle dorsal flexion & $15.0 \pm 5.5$ & $12 \pm 8.2$ & .60 \\
\hline knee flexion & $25.4 \pm 7.8$ & $-.76 \pm 51.8$ & .36 \\
\hline hip flexion & $18.7 \pm 2.1$ & $17.4 \pm 9.4$ & .79 \\
\hline trunk flexion & $5.5 \pm 2.3$ & $11.2 \pm 4.9$ & .08 \\
\hline (right) shoulder extension & $-10.3 \pm 14.7$ & $25.9 \pm 13.7$ & $.01 *$ \\
\hline (right) elbow flexion & $3.6 \pm 7.5$ & $13.7 \pm 17$ & .31 \\
\hline (right) wrist hyper-extension & $-1.0 \pm 10.5$ & $-64.5 \pm 88.2$ & .20 \\
\hline \multicolumn{4}{|l|}{ Action $\left({ }^{\circ}\right)$} \\
\hline ankle plantar flexion & $-87.8 \pm 21.1$ & $-65.29 \pm 9.4$ & .10 \\
\hline knee extension & $-77.5 \pm 13.3$ & $-86.1 \pm 12.5$ & .38 \\
\hline hip extension & $-32 \pm 8.8$ & $-48.7 \pm 21.9$ & .21 \\
\hline trunk extension & $-13.4 \pm 17.9$ & $-20.3 \pm 10.4$ & .53 \\
\hline (right) shoulder flexion & $8.2 \pm 20.1$ & $-7.0 \pm 44.8$ & .56 \\
\hline (right) elbow extension & $-77.0 \pm 8.0$ & $-49.9 \pm 26.8$ & .10 \\
\hline (right) wrist flexion & $-145.9 \pm 40.3$ & $-42.2 \pm 22.6$ & $.00 *$ \\
\hline \multicolumn{4}{|l|}{ Follow-through $\left({ }^{\circ}\right)$} \\
\hline ankle plantar flexion & $61.6 \pm 17.8$ & $41.5 \pm 16.7$ & .15 \\
\hline knee extension & $35.8 \pm 14.3$ & $37.3 \pm 7.9$ & .86 \\
\hline hip extension & $9.2 \pm 6.4$ & $18.8 \pm 18.7$ & .37 \\
\hline trunk extension & $10.8 \pm 21$ & $17.7 \pm 8.9$ & .57 \\
\hline (right) shoulder flexion & $-13.6 \pm 74.6$ & $-20.4 \pm 12.4$ & .86 \\
\hline (right) elbow extension & $50.9 \pm 64.2$ & $25.8 \pm 78.3$ & .64 \\
\hline (right) wrist flexion & $-7.6 \pm 12.0$ & $9 \pm 31.1$ & .36 \\
\hline
\end{tabular}

*significant difference $\mathrm{p}<0.05$ 
Jurnal Keolahragaan 7 (1), 2019 - 5

Agam Akhmad Syaukani, Li Chun Yan

\section{Discussion and Implications}

Temporal Period

The phase of jump shot in this study was proposed according to Satern (1988) which has broadly accepted within basketball practitioners community (Okazaki, Rodacki, \& Satern, 2015) included preparatory, action, and follow-through phase. The temporal variables were constructed similar to the research presented by Nunome et al (2002; Table 2) with a little changes based on jump shot movement characteristic. The mean values showed no significant differences in total time of the jump shot motion between the experienced group and the less-experienced group. Result on duration of the particular phase of the jump shot also indicated that the difference regarding on duration of the jump shot execution between the experienced group and the lessexperienced group was not significant. This finding may indicate that regarding on time spent by players between groups during jump shot execution, the difference were not significant. Therefore, focus should be given more on joint angular velocity and displacement rather than movement duration. However, this study only provides temporal comparison during jump shot in non-contended situation without presence of the opponent. Study conducted by Rojas et al. (2000) suggested that professional basketball player tend to release the ball quickly with higher angle release compared to situation without presence of the opponent. Future study should elaborate this idea and make temporal comparison between the experienced group and the less-experienced group with presence of the opponent.

\section{Kinematics}

This study found that there is significant difference in several kinematic attributes between the experienced group and the less-experienced group. The consideration should be given to the fact that playing or training experience had positive correlation with players' expertise. Expert players are mostly had more consistency in movement selection pattern to perform a successful jump shot (Okazaki \& Rodacki, 2012). This result corroborates earlier research that highlighted the benefit of practice on reducing movement variability in basketball (Button et al., 2003). Miller \& Bartlett (1996) suggested that the guards were tend to have better adaptation consistency of their kinematic patterns during long range shooting as compared to the center who acquired less experience on shooting from greater distance. Significant difference bet-ween groups found in the present study including kinematic parameter in preparatory phase, and action phase of the jump shot (Table 2, Table 3 ).

Table 3. Angular Velocity Data (mean \pm s) for Basketball Players with Different Experience Level

\begin{tabular}{llll}
\hline & Experienced & Less-experienced & $p$-value \\
\hline Preparatory (\%) & & & .41 \\
ankle dorsal flexion & $29.7 \pm 11.1$ & $48.3 \pm 40.5$ & .09 \\
knee flexion & $58.5 \pm 17.9$ & $147.2 \pm 86.5$ & $.01^{*}$ \\
hip flexion & $41.0 \pm 11.6$ & $98.7 \pm 31.6$ & .40 \\
trunk flexion & $13.0 \pm 5.9$ & $27.2 \pm 30.3$ & .12 \\
(right) shoulder extension & $-12.6 \pm 104.3$ & $109.1 \pm 84.8$ & .86 \\
(right) elbow flexion & $21.8 \pm 54.8$ & $27.1 \pm 34.1$ & .84 \\
(right) wrist hyper-extension & $13.1 \pm 45.4$ & $7.8 \pm 18.4$ & $.03 *$ \\
Action (\%) & & & .65 \\
ankle plantar flexion & $-159.5 \pm 27.3$ & $-110.0 \pm 20.8$ & .22 \\
knee extension & $-139.9 \pm 15.9$ & $-143.94 \pm 6.4$ & .75 \\
hip extension & $-57.0 \pm 18.5$ & $-94.3 \pm 51.0$ & .17 \\
trunk extension & $-28.5 \pm 31.9$ & $-34.2 \pm 13.2$ & $.03 *$ \\
(right) shoulder flexion & $41.0 \pm 73.9$ & $-29.7 \pm 50.8$ & $.00 *$ \\
(right) elbow extension & $-149.6 \pm 33.3$ & $-80.2 \pm 36.0$ & \\
(right) wrist flexion & $-182.8 \pm 35.7$ & $-70.2 \pm 36.7$ & .24 \\
Follow-through $\%$ /s) & & & .70 \\
ankle plantar flexion & $169.1 \pm 53.0$ & $122.2 \pm 49.0$ & .37 \\
knee extension & $99.3 \pm 45.5$ & $110.0 \pm 25.4$ & .53 \\
hip extension & $27.7 \pm 13.3$ & $55.5 \pm 55.0$ & .34 \\
trunk extension & $59.7 \pm 10.0$ & $47.6 \pm 34.6$ & .22 \\
(right) shoulder flexion & $-133.3 \pm 144.6$ & $-27.4 \pm 28.3$ & .42 \\
(right) elbow extension & $148.1 \pm 101.9$ & $243.7 \pm 93.8$ & \\
(right) wrist flexion & $-4.1 \pm 64.7$ & $48.5 \pm 102.2$ & \\
\hline
\end{tabular}


Jurnal Keolahragaan 7 (1), 2019 - 6

Agam Akhmad Syaukani, Li Chun Yan

Right-shoulder extension angular displacement. Significant difference was found in right-shoulder extension angular displacement during preparatory phase (Table 2). The lessexperienced group were having larger displacement $\left(25.9 \pm 13.7^{\circ}\right)$ on shoulder extension as compared to their experienced counterpart $\left(-10.3 \pm 14.7^{\circ}\right)$. This result indicated that the lessexperienced group were having more dynamic shoulder action during preparatory phase. However, during preparatory phase which characterized by shoulder extension, shoulder joint displacement in the less-experienced group ideally should be in negative quantity as an indicator of shoulder extension. The time-series curves shown in Figure 1a of the right-shoulder joint angles during preparatory phase $(0-25 \%$, Table 1) between groups shows that lessexperienced group were having upward curve compared to their experienced counterpart. This result suggested that less-experienced participants were having their shooting shoulder flexed during preparatory phase while experienced participants having their shoulder extended. It is suggested that less-experienced participants were not in proper triple threat position and not

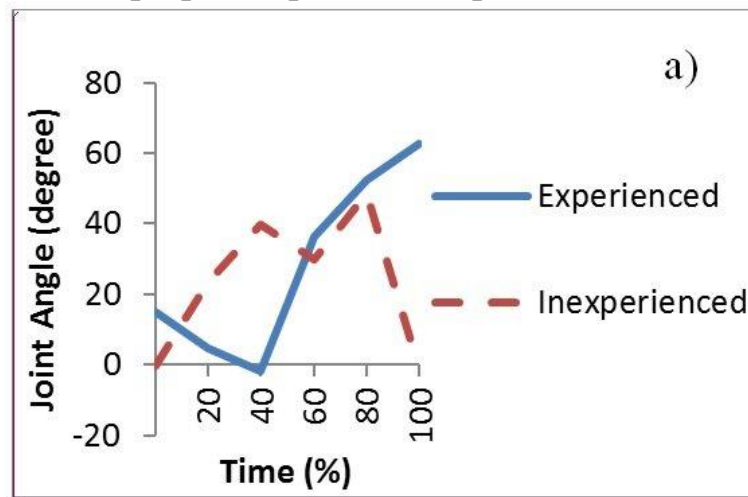

positioned the ball in the shooting pocket, stomach-chest area. Mechanically, shoulder on the shooting hand is useful to create impulse and generate momentum only when it is begin from extend position. Many basketball coach and expert suggested that during preparatory phase the ball should be positioned in the shooting pocket, stomach-chest area, below the shoulders, on the strong side. Shooting pocket is where the shot should starts and where the player holds the ball in the typical offensive basketball stance (triple threat) (Filippi, 2011, p. 16; Hopla, 2012, p. 28). Filippi (2011, p. 16) revealed that the lower the shooting pocket, the more power is achieved. He also suggested that proper shooting pocket combined with proper use of legs provides the power to initiate shooting motion (Filippi, 2011, p. 16). Players who had not placed the ball in a shooting pocket would lose the power of propelling the ball for vertical displacement. Shooting jump shot from mid-range require the player to imply greater angle of entry of the ball by increase the release angle. Increasing the angle of entry of the ball increases the width of the basket (Brancazio, 1981). Thus, increase the possibility of the ball going in the basket.

Figure 1. Temporal course of changes in mean joint angle during (a) right-shoulder flexion $(+)$ extension, and (b) right-wrist flexion (+) -extension in each group.

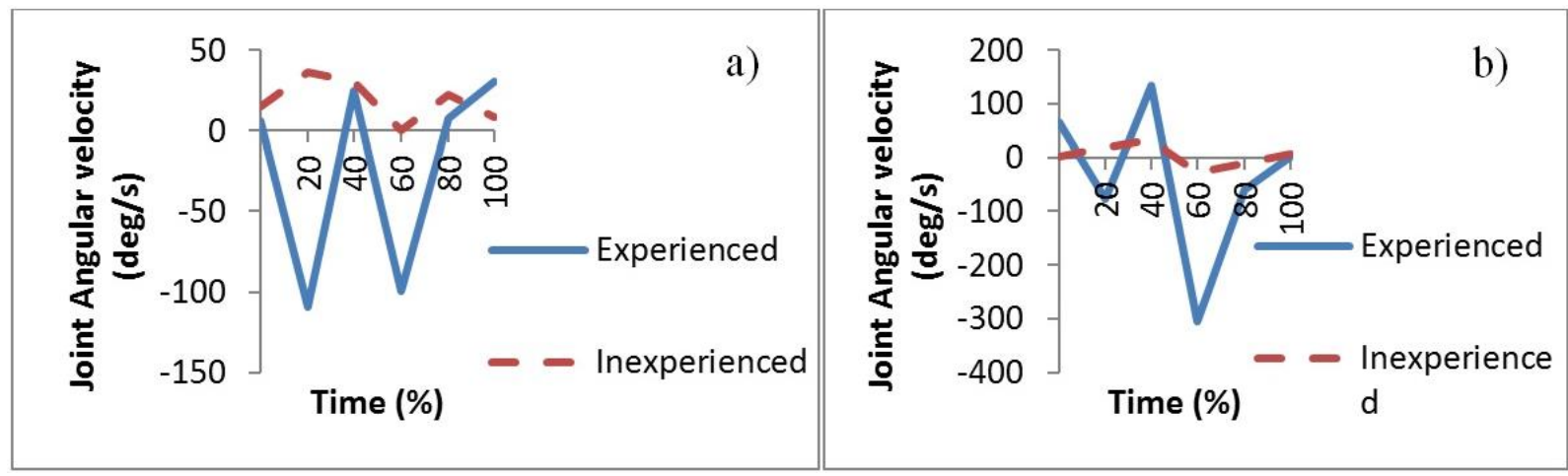

Figure 2. Temporal course of changes in mean joint angle during (a) hip flexion (+)- extension, and (b) ankle flexion (+)- extension. 
Jurnal Keolahragaan 7 (1), 2019 - 7

Agam Akhmad Syaukani, Li Chun Yan

Okubo \& Hubbard (2015) revealed that shoulder flexion-extension contributes to the vertical component of release velocity of the ball while elbow and wrist actions mostly contribute to the horizontal displacement of the ball. Therefore, improper shoulder placement as found in less-experienced player during preparatory phase will not produce enough force to propel the ball vertically. This consideration is especially needed when shooting are executed from far range as the ball need to overcome greater distance toward the rim.

Right-wrist flexion angular displacement. Significant difference was found in right-wrist flexion angular displacement during action phase of jump shot (Table 2). The less-experienced group was found to have smaller displacement during wrist flexion as compared to the experienced group. Wrist flexion in the shooting hand is important to apply backspin on the ball. The backspin applied in a jump shot serves to reduce horizontal velocity of the ball if it strikes the rim, or causes the ball to deflect downward if it strikes the backboard (Knudson, 1993). Application of backspin to the ball also promotes the normal arc during the ball flight. Therefore, the effect of ball spin on the flight of the ball has been estimated to be one of the factors that statistically related to shooting success (Yates \& Holt, 1983). Although this study excluding the analysis of the ball kinematics, it can be speculated that insufficient wrist flexion displacement on the shooting hand will result in the absence of ball spin during the shot.

The time-series curves of the right-wrist joint angles during action phase $(25-75 \%$, Table 1) between groups shows that less-experienced group were having relatively little displacement compared to their experienced counterpart. Experienced group were more dynamic in rightwrist flexion during action phase with wrist fully flexed in the end of the shooting, indicated from the curve shown in Figure 1b. This suggested that less-experienced participants were not applied optimal backspin on the ball in which very important in every basketball shooting.

Hip flexion angular velocity. Significant difference was found in hip flexion angular velocity during preparatory phase of shooting jump shot (Table 3). The experienced group was found to have slower hip flexion as compared to their less-experienced counterparts. The timeseries curves shown in Figure 2a of the hip joint angles during preparatory phase $(0-25 \%$, Table 1$)$ between groups shows that less-experienced group were having upward curve compared to their experienced counterpart. Hip flexion during preparatory phase is necessary to initiate the counter-act movement and generate upward force through elastic potential energy of the muscle and tendon. It can be speculated that slower hip flexion found in the experienced group was the way to establish a stable stance before taking the shot. Filippi (2011, p. 17) revealed in set shooting and free throw shooting should be smooth and continuous that the pause barely occurs on high skilled players. However, such approach will not be effective in jump shot with presence of opponent. Jump shot need to be executed in rapid motion while maintain proper mechanic in order to avoid opponent's block without sacrificing the ball alignment with the basket.

Ankle plantar flexion angular velocity. Significant difference was found in ankle plantar angular velocity during action phase of shooting jump shot (Table 3). The experienced group was found to have a faster plantar flexion as compared to the less-experienced group. The time-series curves shown in Figure $2 b$ of the hip joint angles during action phase (25-75\%, Table 1) between groups shows that less-experienced group were relatively having little downward peak curve compared to their experienced counterpart. It is indicated that less-experienced subject were doing ineffective plantar flexion movement. Ankle plantar flexion initiates the vertical jumping movement. Plantar flexion shares the function as vertical jump generators with knee extension. They both are major determinant for height release of the ball (Miller \& Bartlett, 1996). Greater height release permits the player to use smaller release angle (Okazaki et al., 2015). Therefore, reduce the necessity to execute the ball with the upper limb higher movement velocity. 
Jurnal Keolahragaan 7 (1), 2019 - 8

Agam Akhmad Syaukani, Li Chun Yan

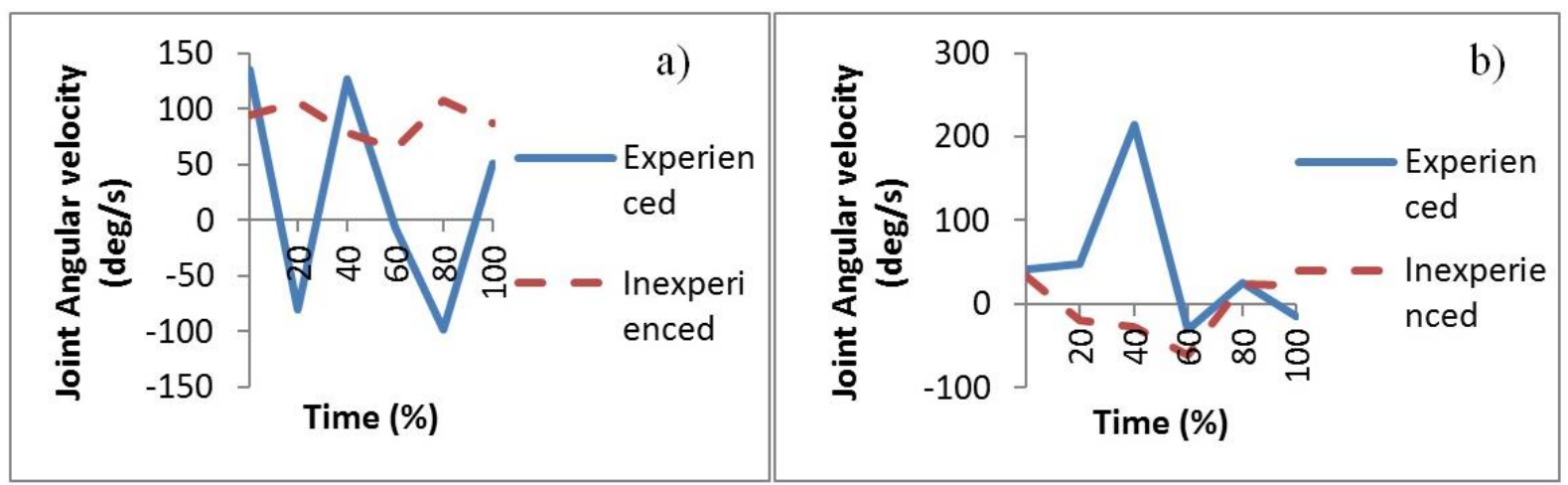

Figure 3. Temporal course of changes in mean joint angle during (a) right-elbow flexion $(+)-$ extension, and (b) right-wrist flexion (+)- extension.

Right-elbow extension angular velocity. Significant difference was found in the rightelbow extension angular velocity during action phase of shooting jump shot (Table 3 ). The experienced group was found to have faster elbow extension. The time-series curves shown in Figure 3a of the right-elbow joint angles during action phase $(25-75 \%$, Table 1$)$ between groups shows that less-experienced group were relatively having a static curve (little magnitude) compared to their experienced counterpart. Despite no significant difference found in rightelbow angular displacement during action phase between groups, it is indicated that elbow were not moving faster enough through its range of motion in the less-experienced group. Horizontal ball propelling force are mainly comes from elbow extension. Therefore insufficient impulse resulted from slower elbow extension may result in failure to overcome the long trajectory to reach the basket. Okazaki \& Rodacki (2012) revealed that as the shooting distance increased, the ball release velocity also increased.

Right-wrist flexion angular velocity. Significant difference was found in the rightwrist flexion angular velocity during action phase of shooting jump shot (Table 3 ). The experienced group was found to have faster wrist flexion movement. The time-series curves shown in Figure $3 b$ of the right-wrist joint angles during action phase (25-75\%, Table 1) between groups shows that less-experienced group were relatively having a static curve (little magnitude) compared to their experienced counterpart. The experienced group recorded high peak velocity at $+214.7^{\circ}$ s (Figure $3 \mathrm{~b}$ ) and it was relatively higher compared to the less-experienced group. Higher speed rate of wrist flexion promotes an effective ball spin during the shot. Regarding on higher speed release of the ball found in farther shooting distance (Okazaki \& Rodacki, 2012), on the well- known speed-accuracy trade-off (Fitts, 1954; Meyer, Abrams, Kornblum, Wright, \& Keith Smith, 1988) the shooting with higher speed of release may also influenced the loss of accuracy. Thus, to overcome this problem highly skilled players were observed to apply spin to the ball and increase ball rotation during flight. There are advantages to apply backspin highlighted by some authors as the following: (a) reduce the horizontal velocity of the ball, (b) make a downward deflection when the ball hit the backboard or the ring, in case the ball does not goes into the basket, the ball with backspin will fall near the backboard to open chance for offensive rebound and (c) preserves the velocity of the ball during flight (Hamilton \& Reinschmidt, 1997; Knudson, 1993). A low release velocity generated by applying backspin to the ball was associated with decreased movement variability of the body segments, thereby increasing movement consistency (W G. Darling \& Cooke, 1987; W. G. Darling \& Cooke, 1987). Player who had low release velocity has the advantage to perform movement corrections using visual and proprioceptive feedback and generate less neural noise (Schmidt, Zelaznik, Hawkins, Frank, \& Quinn, 1979).

\section{CONCLUSION}

In conclusion, based on the findings of this present comparative study, there is different kinematic profile between the experienced group and the less-experienced group during jump shot in basketball. The differences including kinematic parameters (angular velocity and angular displacement) in the ankle joint angle, hip joint angle, shoulder joint angle, elbow joint angle, and wrist joint angle. Given the result of this study, proper jump shot should be characterized by rapid movement and optimum displacement both 
Jurnal Keolahragaan 7 (1), 2019 - 9

Agam Akhmad Syaukani, Li Chun Yan

for lower and upper extremities especially during preparatory and action phase.

\section{REFERENCES}

Brancazio, P. J. (1981). Physics of basketball. American Journal of Physics, 49(4), 356365. https://doi.org/10.1119/1.12511

Button, C., Macleod, M., Sanders, R., \& Coleman, S. (2003). Examining movement variability in the basketball free-throw action at different skill levels. Research Quarterly for Exercise and Sport, 74(3), 257-269.

https://doi.org/10.1080/02701367.2003.10 609090

Çetin, E., \& Muratl1, S. (2014). Analysis of jump shot performance among 14-15 year old male basketball player. Procedia - Social and Behavioral Sciences, 116, 2985-2988. https://doi.org/10.1016/J.SBSPRO.2014.0 1.693

Darling, W. G., \& Cooke, J. D. (1987). Changes in the variability of movement trajectories with practice. Journal of Motor Behavior, 19(3), 291-309. https://doi.org/10.1080/00222895.1987.10 735414

Darling, W. G., \& Cooke, J. D. (1987). Movement related EMGs become more variable during learning of fast accurate movements. Journal of Motor Behavior, 19(3),

311-331. https://doi.org/10.1080/00222895.1987.10 735415

Filippi, A. (2011). Shoot like the pros: The road to a successful shooting technique. Triumph Books.

Fitts, P. M. (1954). The information capacity of the human motor system in controlling the amplitude of movement. Journal of Experimental Psychology, 47(6), 381-391. https://doi.org/10.1037/h0055392

Hamilton, G. R., \& Reinschmidt, C. (1997). Optimal trajectory for the basketball free throw. Journal of Sports Sciences, 15(5), 491-504. https://doi.org/10.1080/026404197367137

Hess, C. (1980). Analysis of the jump shot. Athletic Journal, 61(3), 30-32.

Hopla, D. (2012). Basketball shooting. Human Kinetics.

Knudson, D. (1993). Biomechanics of the basketball jump shot-six key teaching points. Journal of Physical Education, Recreation \& Dance, 64(2), 67-73. https://doi.org/10.1080/07303084.1993.10 606710

Meyer, D. E., Abrams, R. A., Kornblum, S., Wright, C. E., \& Keith Smith, J. E. (1988). Optimality in human motor performance: ideal control of rapid aimed movements. Psychological Review, 95(3), 340. https://doi.org/10.1037/0033295X.95.3.340

Michaud-Paquette, Y., Magee, P., Pearsall, D., \& Turcotte, R. (2011). Whole-body predictors of wrist shot accuracy in ice hockey: a kinematic analysis. Sports Biomechanics, 10(1), 12-21. https://doi.org/10.1080/14763141.2011.55 7085

Miller, S., \& Bartlett, R. (1996). The relationship between basketball shooting kinematics, distance and playing position. Journal of Sports Sciences, 14(3), 243-253. https://doi.org/10.1080/026404196087277 08

Okazaki, V. H. A., \& Rodacki, A. L. F. (2012). Increased distance of shooting on basketball jump shot. Journal of Sports Science and Medicine, 11(2), 231-237. Retrieved from https://www.jssm.org/hfabst.php?id=jssm $-11-231 . x m l$

Okazaki, V. H. A., Rodacki, A. L. F., \& Satern, M. N. (2015). A review on the basketball jump shot. Sports Biomechanics, 14(2), 190-205. https://doi.org/10.1080/14763141.2015.10 52541

Okubo, H., \& Hubbard, M. (2015). Kinematics of arm joint motions in basketball shooting. Procedia Engineering, 112, 443-448. https://doi.org/10.1016/J.PROENG.2015. 07.222

Rojas, F. J., Cepero, M., Ona, A., \& Gutierrez, M. (2000). Kinematic adjustments in the basketball jump shot against an opponent. Ergonomics, 43(10), 1651-1660. https://doi.org/10.1080/001401300750004 069

Satern, M. (1988). Performance EXCELLENCE: Basketball: Shooting the jump shot. Strategies: A Journal for Physical and Sport Educators , 1(4), 9-11. https://doi.org/10.1080/08924562.1988.10 
Jurnal Keolahragaan 7 (1), 2019 - 10

Agam Akhmad Syaukani, Li Chun Yan

591612

Schmidt, R. A., Zelaznik, H., Hawkins, B., Frank, J. S., \& Quinn, J. T. (1979). Motor-output variability: a theory for the accuracy of rapid motor acts. Psychological Review, 47(5), 415-451.

Struzik, A., Pietraszewski, B., \& Zawadzki, J. (2014). Biomechanical analysis of the jump shot in basketball. Journal of Human Kinetics, 42(1), 73-79. https://doi.org/10.2478/hukin-2014-0062
Wissel, H. (2011). Basketball: Steps to success. Human Kinetics Publishers.

Yates, G., \& Holt, L. E. (1983). The development of multiple linear regression equations to predict accuracy in basketball jump shooting. In International Symposium on Biomechanics in Sports: Conference Proceedings Archive (Vol. 1). Retrieved from https://ojs.ub.unikonstanz.de/cpa/article/view/886 